\author{
Cadernos de \\ ESTUDOS LINGï̈ISTIICOS - (55.2), Campinas, Jul./Dez. 2013
}

\title{
ENTRE LÁPIS E TECLAS: SELECIONANDO E COMBINANDO LETRAS
}

\author{
FERNANDA MARIA PEREIRA FREIRE ${ }^{1}$ \\ ALLINE KOBAYASHI ${ }^{2}$ \\ BRUNA LEITE GARCIA ${ }^{3}$ \\ MARIA IRMA HADLER COUDRY ${ }^{4}$
}

\begin{abstract}
RESUMO: O artigo analisa e discute dados do trabalho linguístico-cognitivo do sujeito RM (10a4m) com a fala, a leitura e a escrita em diferentes contextos de uso sociocultural da linguagem, incluindo aqueles mediados por computadores, com base na teorização da Neurolinguística Discursiva e, em especial, no conceito de organização bipolar da linguagem. Segundo a escola, RM apresenta dificuldades de leitura/escrita e se dispersa facilmente das tarefas escolares. Observamos que o sujeito apresentava dúvidas recorrentes relacionadas à representação gráfica das letras, razão pela qual iniciamos um trabalho com vários tipos de letras usadas para ler e escrever, manuscritas e impressas, incluindo aquelas produzidas por meio do computador, aproveitando o seu potencial material e simbólico. Os resultados mostram que a materialidade do computador, isto é, a disposição das letras no teclado, a interface do software, a verticalização da tela e o tipo de letra impuseram outras condições/restrições à escrita de RM, aqui interpretadas como uma alternância entre seleções e combinações condicionadas por fatores socioculturais, produzindo um efeito positivo na sua relação com a escrita.
\end{abstract}

PALAVRAS-CHAVE: escrita, computador, Neurolinguística

ABSTRACT: The article analyzes and discusses datas of cognitive-linguistic work of RM (10y4m) with speech, reading and writing in different sociocultural contexts of use of language, including those mediated by computers, based on the theory of Discursive Neurolinguistics and, in particular, on the concept of bipolar organization of language. According to the school, RM has difficulty for reading/ writing and disperses easily from schoolwork. We observed that he had recurring doubts related to graphical representation of the letters, which is why we started working with various types of letters (handwritten and printed), in reading and writing activities including those produced by computer taking advantage of its physical and symbolic potential. The results show that the materiality (?) of the computer, ie the arrangement of letters on the keyboard, the software interface, the vertical screen and the letter type, imposed other conditions/restrictions for RM's written, interpreted here as a alternation between selections and combinations conditioned by sociocultural factors, producing a positive effect on his relationship with writing.

KEY-WORDS: writing, computer, Neurolinguistics

\footnotetext{
${ }^{1}$ ffreire@unicamp.br

2 allinekobayashi@gmail.com

${ }^{3}$ bruna.lgarcia@yahoo.com.br

${ }^{4}$ coudry@iel.unicamp.br
} 


\section{INTRODUÇÃO}

Este artigo analisa e discute - com base nos pressupostos teóricometodológicos da Neurolinguística Discursiva, considerando de maneira especial o funcionamento bipolar da linguagem nos termos de Jakobson (1955/1970; 1969) - dados provenientes do trabalho linguístico-cognitivo realizado por RM, um garoto de $10 \mathrm{a} 4 \mathrm{~m}$, com a fala, a leitura e a escrita, em diferentes contextos de uso sociocultural da linguagem, incluindo aqueles mediados por computador ${ }^{5} \mathrm{e}$ que aqui serão focalizados de maneira especial. RM vem sendo acompanhado longitudinalmente de forma individualizada desde setembro de $2010^{6}$, em virtude de uma queixa escolar relacionada às dificuldades que apresenta para ler e escrever, dispersando-se das atividades escolares com facilidade.

Como foi dito, este acompanhamento se faz a partir das orientações teóricometodológicas da Neurolinguística Discursiva (ND), que tem como objeto de estudo o funcionamento da linguagem e sua relação com outras atividades cognitivas em meio à vida em sociedade em sujeitos que se encontram ou não em estados patológicos ${ }^{7}$ (COUDRY, 1993). Seu movimento teórico resulta da articulação de conceitos de autores que pensam a linguagem, o cérebro/mente e o sujeito como construtos socioculturais, diferenciando-se de outras áreas com as quais dialoga, como a Fonoaudiologia (organicista/tradicional ${ }^{8}$ ) e a Neurologia, pelo fato de assumir um posto de observação predominantemente linguístico (COUDRY e FREIRE, 2010).

A qualificação discursiva está relacionada ao modo como a linguagem se apresenta: heterogênea, polissêmica e indeterminada, por um lado (FRANCHI, 1977/1992) e, determinada ideológica e historicamente, por outro (BAKHTIN, 1929/1999). Tal condição se dá a conhecer quando é posta em funcionamento em meio a práticas sociais de uso, daí a centralidade do conceito de interlocução em

${ }^{5}$ Este artigo apresenta parte dos resultados do projeto "Explorando o uso de dispositivos móveis em práticas sociais de leitura e escrita", coordenado por Fernanda Maria Pereira Freire (Faepex/ UNICAMP) que se vincula a dois outros: (i) Projeto Integrado em Neurolinguística: práticas com a linguagem e documentação de dados (IEL-CNPq 307227/2009-0, Profa Dra Maria Irma Hadler Coudry) e (ii) Um Computador por Aluno - UCA (NIED-MEC/Prof. Dr. José Armando Valente).

${ }^{6}$ Participam deste acompanhamento, além da primeira autora, investigadora identificada pela sigla Iff, duas alunas da Unicamp: Iak, pós-graduanda em Linguística no Instituto de Estudos da Linguagem, sob orientação da Profa Coudry e co-orientação de Fernanda M. P. Freire, e integrante do Projeto "Explorando o uso de dispositivos móveis em práticas sociais de leitura e escrita" e Ibg, atualmente graduanda do curso de Linguística, bolsista de IC orientada pela Profa Dra Coudry e integrante do Projeto Integrado em Neurolinguística, também autoras deste artigo. Na análise de alguns dos dados aqui apresentados usaremos a $3^{\mathrm{a}}$ pessoa do singular para referir aos encontros realizados por Iff.

${ }^{7}$ A teorização da Neurolinguística de tradição discursiva começa nos anos 80 com a tese da Profa Dra Maria Irma Hadler Coudry - Diário de Narciso: discurso e afasia (1986) - com sujeitos afásicos e, desde então, vem sendo continuamente reformulada e expandida por meio das várias edições do Projeto Integrado em Neurolinguística: práticas com a linguagem e documentação de dados (CNPq: 307227/2009-0), sob sua coordenação.

${ }^{8}$ A ND considera como Fonoaudiologia Tradicional aquela que não dialoga com teorias linguísticas. 
seus estudos (COUDRY e FREIRE, 2010). Da mesma forma, para dar conta da natureza complexa do funcionamento das línguas naturais, a ND assume um modelo de cérebro também complexo, tal como é proposto por Vygotsky (1934/1984), Luria (1981) e Freud, em seus estudos neurofisiológicos (1891/1973).

Os dados que aqui serão apresentados e discutidos foram produzidos por RM, atualmente aluno do $6^{\circ}$ ano (antiga $5^{\mathrm{a}}$ série) do Ensino Fundamental de uma escola estadual do município de Campinas (SP), encaminhado em abril de 2010 ao Centro de Convivência de Linguagens (CCazinho), que funciona no Instituto de Estudos da Linguagem da Universidade Estadual de Campinas. Segundo a carta de encaminhamento da escola, assinada pela coordenadora pedagógica, RM apresenta dificuldades no aprendizado: "não consegue processar os níveis de alfabetização, reconhecendo apenas as letras do alfabeto, com retenção de memória curta, o que dificulta a articulação cognitiva, ainda com intervenção individualizada da professora". O aluno havia frequentado aulas de reforço no ano anterior, mas não havia conseguido "organizar-se no sistema alfabético de leitura e escrita com autonomia", tampouco compreender o "sistema de numeração decimal". À época do encaminhamento, RM recebia atendimento diferenciado em sala de aula, "pois necessita de apoio constante para a realização de tarefas simples", além de aulas semanais de reforço oferecidas por uma professora alfabetizadora, "sem muito sucesso em seu desenvolvimento". O encaminhamento informa ainda que RM "se expressa muito bem oralmente, participa e questiona na hora da leitura realizada pela professora de classe, porém não consegue registrar e nem interpretar ainda que à sua maneira". E continua: "notamos que se dispersa facilmente especialmente nas atividades de registro, deixando-as sem terminá-las".

O CCazinho, criado em agosto de 2004 pela Prof ${ }^{a}$ Coudry, acolhe crianças e jovens que recebem diagnósticos neurológicos variados (dificuldades de aprendizagem, dislexia, transtorno do déficit de atenção com e sem hiperatividade (TDA/H), problemas no processamento auditivo, deficiência mental), bem como crianças que apresentam dificuldades escolares, muitas vezes confundidas com patologias que afetam a leitura e a escrita, como é o caso de RM. Atualmente, cerca de 25 sujeitos que se veem nessas condições frequentam os encontros semanais em grupo, com duração de $2 \mathrm{~h}$, e/ou participam de acompanhamentos longitudinais individuais. Os trabalhos coletivo e individualizado são mediados por vários tipos de cuidadores: alunos das disciplinas AM 034 e AM 0459; bolsistas de Apoio Técnico do Projeto Integrado em Neurolinguística (CNPq); alunos de Iniciação Científica, Mestrado e Doutorado; e demais pesquisadores que participam do Projeto Integrado em Neurolinguística.

Tomando a interlocução como lugar de teorização e de práticas com a linguagem que mobilizam a fala, a leitura e a escrita, o CCazinho se posiciona contra o uso abusivo de tais diagnósticos (formais ou não) - em geral, apressados e vagos (COUDRY, 2006) - por meio da inserção das crianças/jovens “em atividades

${ }^{9}$ Respectivamente, Leitura e escrita: acompanhamento de crianças e jovens I $\left(1^{\circ}\right.$ semestre letivo) e Leitura e escrita: acompanhamento de crianças e jovens II ( $2^{\circ}$ semestre letivo), ambas oferecidas pelas professoras Dras. Maria Irma Hadler Coudry e Sônia Sellin Bordin a todos os alunos de graduação da Universidade. 
interessantes, mediadas pelo outro e pelo sentido, que as envolvem, que provocam o fazer, o brincar/criar e o refletir" (COUDRY, 2009, p. 20). É com este espírito que propomos também atividades discursivamente orientadas que fazem uso de computadores que atuam como mediadores coadjuvantes da relação da criança com a leitura e a escrita (FREIRE, 2012; 2011).

Neste artigo, apresentamos o sujeito RM e algumas faces da sua relação com o mundo das letras, em seu primeiro ano de acompanhamento longitudinal, no CCazinho, bem como o conceito de funcionamento bipolar da linguagem (JAKOBSON, 1955/1970; 1969) com o propósito de analisar dados-achados (COUDRY, 1996) produzidos por RM na sua interação com o computador em momentos de escrita. Nesses dados se pode observar seu movimento em direção à seleção e combinação de letras na tentativa de compreender o sistema de escrita alfabética.

\section{O SUJEITO RM E SUA RELAÇÃO COM A LINGUAGEM}

Ao longo do acompanhamento longitudinal, pudemos conhecer RM. Na nossa relação com a criança e com a sua família, por meio dos encontros semanais, soubemos que RM convive com muitos adultos. Filho único de pais separados, RM mora na casa da avó materna, onde moram também sua mãe e uma prima adulta. A mãe trabalha durante o dia e, muitas vezes, também no período da noite, sobrando-lhe pouco tempo para se dedicar ao filho. A mãe de RM lamenta ausência do pai da criança, com quem mantém uma relação conflituosa ${ }^{10}$. De maneira geral, os familiares têm dificuldade para impor limites ao comportamento de RM, talvez pelo fato de o garoto apresentar um quadro de epilepsia controlado. Em função da falta de limites, observamos, tanto nas sessões individuais quanto nas coletivas, que RM se mostra, muitas vezes, inadequado do ponto de vista social: corre, pula, chama a atenção dos adultos, fala mais do que deve, responde pelo outro, faz brincadeiras sem graça. No contato com ele, percebemos ainda que é muito mimado e que consegue tudo o que deseja, celular, brinquedos caros, laptop, teclado, embora a família tenha uma situação financeira apenas regular. Para driblar o seu excesso de energia e mantê-lo ocupado, até o início de 2012 a mãe o mantinha em aulas de kumon e kung fu. Com a participação da mãe de RM nas reuniões do Grupo de Mães do CCazinho ${ }^{11}$, que acontecem simultaneamente ao atendimento coletivo das crianças, essas atividades foram suspensas e a mãe

${ }^{10}$ Entre abril de 2010 e 2011 RM foi acompanhado por uma psicóloga. Em seu relatório, datado de setembro de 2010, ela diz perceber "muita negação de sentimento, fruto da relação familiar conturbada entre os pais. Situação que se intensificou no período em que ele entrou no ensino fundamental. No momento, os pais passam por um período de entendimento". E ainda: "percebi, em relação à rotina, às regras e limites passados a RM que não há atitudes que estimulem a responsabilidade e o crescimento pessoal". Em abril de 2012, o pai de RM sofreu um acidente automobilístico e foi cuidado pela ex-esposa. Desde então, o casal tenta se reconciliar.

${ }^{11}$ A participação da mãe e/ou de um responsável pela criança nas reuniões semanais é condição para a permanência da criança no CCazinho. 
passou a se dedicar mais sistematicamente a brincar e a ler/escrever com o filho. Em linhas gerais, podemos dizer que RM é uma criança esperta, curiosa, sedutora e desorganizada, seja para se portar socialmente, fazer uso do espaço gráfico ou realizar suas atividades cotidianas.

Veja-se, a título de exemplo, o desenho que RM produziu enquanto contava para Iff, em nosso primeiro encontro, o que fazia na escola. Perguntado se gostava de ir à escola e se tinha amigos, RM nomeia alguns e esclarece que um deles não era propriamente um amigo, era da classe. Começa, então, a contar - enquanto desenha - uma brincadeira que fazem na escada da escola (Dado 1).

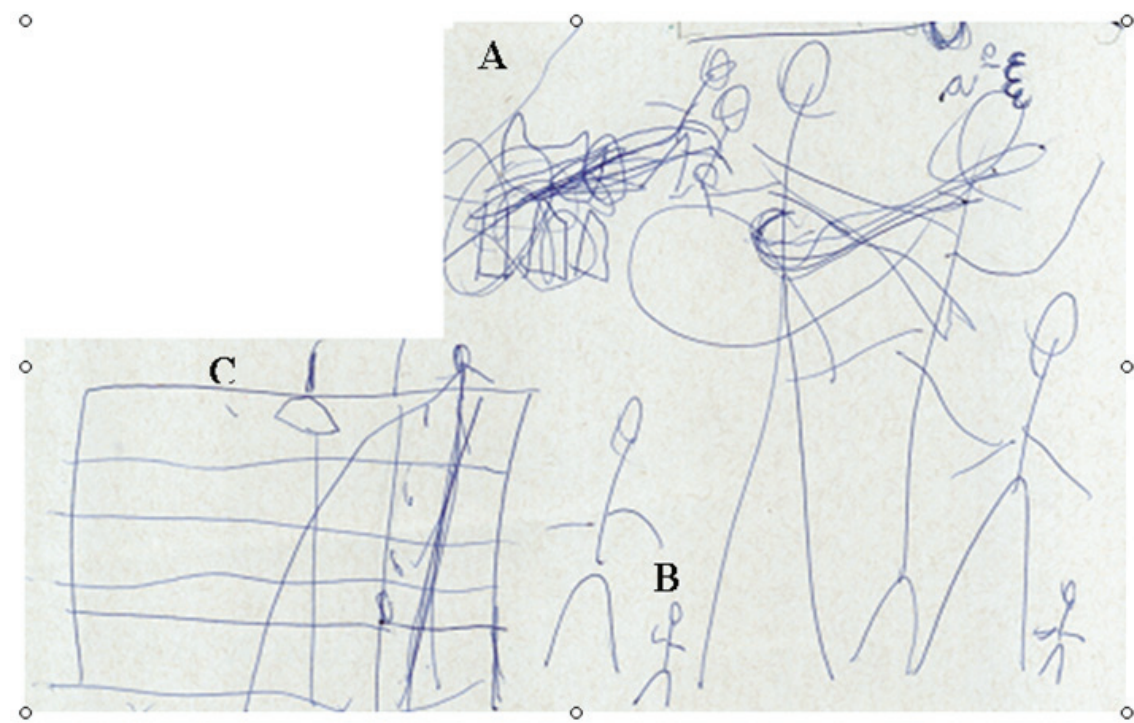

Dado 1 - [28/09/2010] Primeiro encontro com RM (8a11m; $3^{\circ}$ ano EF)

O desenho mostra as crianças pulando a escada (indicado por A). RM segue desenhando os meninos para mostrar quem é mais alto do que quem (B). Como Iff não compreende toda a narrativa, $\mathrm{RM}$ tenta redesenhar a tal escada $(\mathrm{C})$. Ao terminar, rabisca sobre os desenhos que fez.

Este primeiro encontro nos faz pensar que, embora RM seja desinibido e tenha um bom repertório lexical, sua fala é dirigida a si mesmo, pouco considerando seu interlocutor. A pergunta do outro parece não ser suficiente para ajudá-lo a retomar o dito e reorganizar seu querer-dizer (BAKHTIN, 1952-53/1997). Os desenhos aparecem, supomos, no lugar de operações linguísticas (GERALDI, 1991/1993) de esclarecimento e de retomadas, típicas de atividades epilinguísticas (COUDRY, 1986/1989) e servem como referência para organizar sua narrativa.

No encontro seguinte, foi a vez de conversarmos a respeito das reformas que estavam acontecendo em sua casa. RM falou sobre como é a casa, com quem mora, como é o seu quarto, onde guarda seus brinquedos, onde estuda. Descreve a disposição dos cômodos e, quase imediatamente, de posse de uma borracha, 
começa a desenhar com ela sobre a mesa. Com base no que havia observado no encontro anterior, Iff pega lápis e papel e passa a desenhar o que entende do que ele lhe diz, dando materialidade à sua interpretação. Como não concorda com o tamanho da cozinha que Iff desenha, RM assume também a função de desenhar. Por fim, Iff numera os cômodos e juntos escrevem uma legenda (Dado 2).

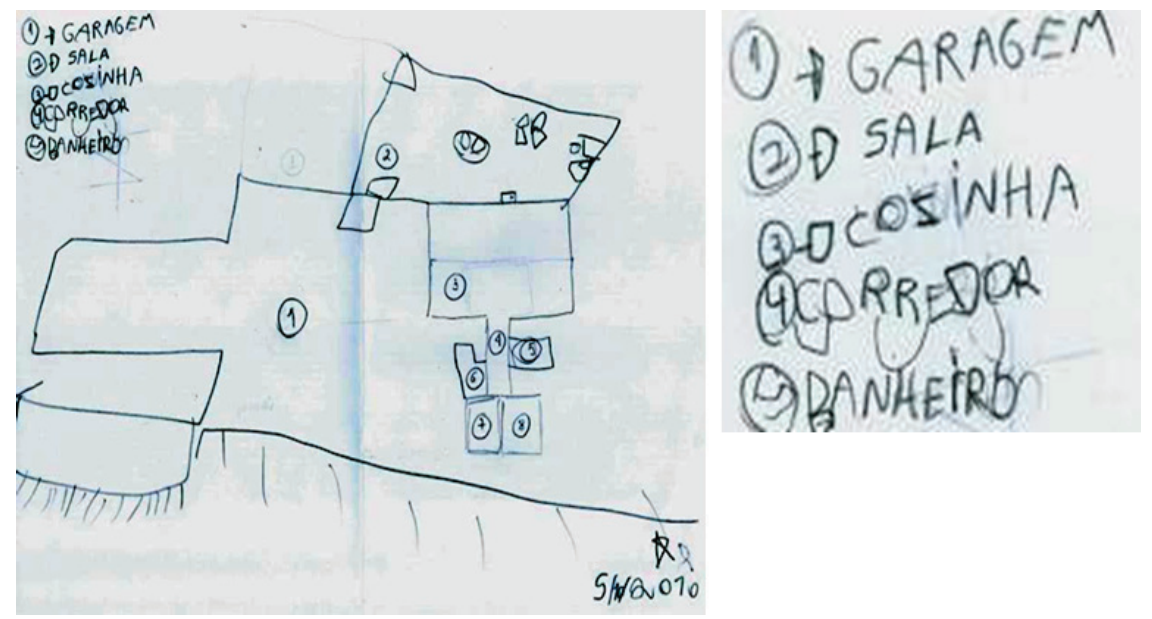

Dado 2 - [05/10/2010] Segundo encontro com RM (8a11m; $3^{\circ}$ ano EF)

Escrevem juntos porque se trata de uma escrita dialogicamente construída. RM diz em voz baixa para si mesmo, várias vezes, parte da palavra, [Ga], ao escrever garagem e, em seguida, diz para Iff os nomes das letras que a compõem [3ə] e [a], aguardando sua aprovação. Essa estratégia se repete para todas as sílabas da palavra garagem e sala. Ao escrever cozinha, diz baixinho, várias vezes, [Ku], e pergunta "como faz?", demonstrando certa intuição de que havia alguma coisa diferente. Iff diz que falamos [Kuzina], mas escrevemos cozinha. Sozinho, desenha as letras "C" e "O". Em seguida, diz baixinho [zi] e, para Iff, diz [Esə] e [i], referindo-se aos nomes das letras "S" e "I". Iff diz que não é com a letra "S" e pergunta qual outra letra poderia representar esse mesmo som. Prontamente, diz [zə], desenhando a letra " $Z$ " de forma invertida. Quando revê o seu traçado, diz que se parece com a letra "N". A representação ortográfica da sílaba "NHA" é mais trabalhosa para RM por conter duas consoantes e uma vogal, e não uma vogal e uma consoante, padrão silábico com o qual está mais familiarizado. A reflexão de Abaurre (2001) sobre indícios de construção da hierarquia silábica em dados de escrita inicial indica que, tal como muitas crianças, RM não consegue, nesse momento da aquisição da base alfabética, "resolver, na escrita, o problema da correta representação dos segmentos que ocupam posições em sílabas com estrutura mais complexa do que CV" (ABAURRE, 2001, p.65).

$\mathrm{O}$ que vemos, pois, nos dados é que RM faz erros comuns aos iniciantes na escrita: fia-se nos sons que produz na fala para representar a palavra ortograficamente (cuzinha); confunde letras que podem representar um mesmo 
som (cosinha); tem dúvidas em relação à representação ortográfica que exige mais do que duas letras (garagem, banheiro). Percebemos também dúvidas relacionadas ao traçado das letras. Ao desenhá-las, seus gestos seguem uma orientação pouco usual. Por exemplo, para escrever a letra "I", RM faz o traço de baixo para cima e depois o pingo, ou, para desenhar um " $\mathrm{D}$ ”, ele faz primeiro a curva de baixo para cima e depois o traço, também de baixo para cima. Há vários traçados de letras que ele confunde - (s/z; b/d; v/z, etc) - ao escrever em letra bastão, com a qual se sai melhor em comparação à cursiva, embora, em geral, ele misture as duas e a última seja mais laboriosa. Observamos ainda que RM faz algumas reflexões metalinguísticas (COUDRY, 1986/1989), por exemplo, ao perceber a equivalência de sons entre as letras " $S$ "e " $Z$ " em alguns contextos, ao perceber a semelhança entre formas de letras, como no caso de " $\mathrm{Z}$ " e "N". Tais reflexões, no entanto, aparecem como dificuldades a serem enfrentadas no ato mesmo de escrever. $\mathrm{O}$ desenho de "B"e "D" é uma dúvida que ainda permanece e que só é resolvida no momento em que a escrita passa pela fala, isto é, ao ler em voz alta o que escreve, ele se dá conta de que usou uma no lugar da outra.

$\mathrm{Na}$ aproximação com a história do sujeito, pedimos a ele que nos mostrasse seus cadernos escolares. Diferentemente do que acontece no CCazinho, onde a criança pode escrever usando diferentes formatos de letras, ensaiar seus traços, fazer suposições e comparações, na escola, em determinado momento do processo, o aluno é convocado a escrever com letra manuscrita suas lições e a copiar da lousa a caligrafia da professora. É o que mostra o Dado 3, apresentado em 3 colunas: a da esquerda mostra a página do caderno de RM; a do meio transcreve - tal como conseguimos decifrar - o modo como RM escreve o que vê/ lê e, finalmente, a coluna da direita, que mostra o que a professora supostamente escreveu na lousa. 


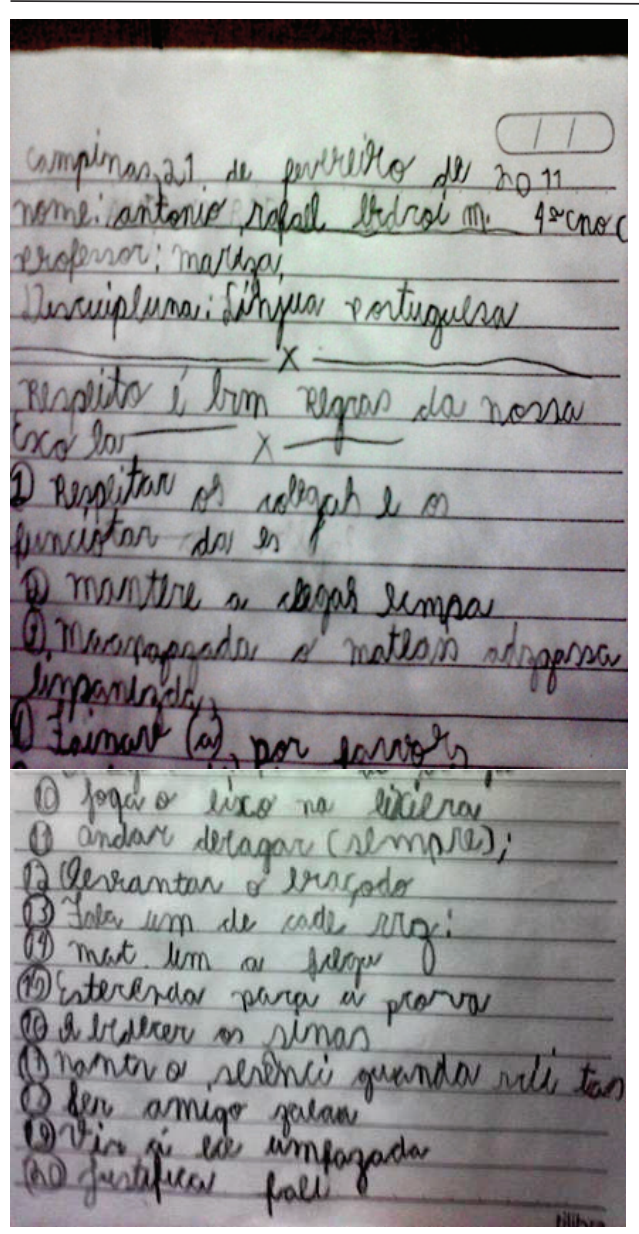

Campinas, 21 de

fevereiro de 2011

Nome:

$4^{\mathrm{a}}$ ano $\mathrm{C}$

Professor:

Discicipluna:

Línjua

Portuguesa

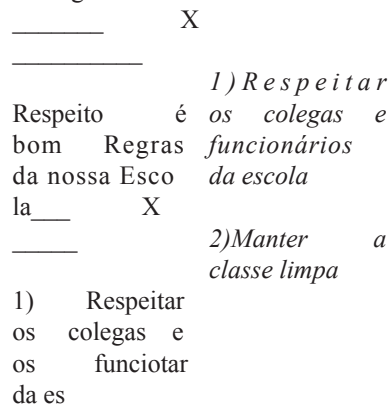

2) Mantere a favor

clegas limpa

$\begin{array}{ll} & \text { 10) Jogaro } \\ 3) & \text { lixo } \\ \text { Marapazaad } & \text { lixeira }\end{array}$

a o mateass adzgassa 11) Andar linpanizda $\quad d e v a g a r$ 4) Fainare (a) (sempre) por favors

12) Levantar o braço

10) Joga o 13) Falar um lixo na lixiera de cada vez

11) andar deragar 15) Estudar (sempre); para a prova

12) Oevantar o braçodo 13) Fala um de cade viz: 16) 14) Mat. um a felgu

Obedecer os sinais

15) Esterenda para a prorra

17) Manter o silêncio quando vier 16) $Q$ bedecer os sinas visitas 18) Ser um amigo zeloso

17) Mantr o serênci guanda vii tas 19) $\mathrm{Vir} \quad \grave{a}$ escola 18) Ser amigo $o$ uniformizad zalau 20) 19) Vir á ece Justificar as umfazada faltas

20) Justifica fali

Dado 3 - [21/02/2011] Cópia da lousa feita por RM (9a4m; 4ªno EF) 
O Dado dá uma ideia do que RM faz na escola e como lá lida com as atividades de leitura e de escrita: nesse caso, trata-se de uma aula no início do ano letivo, na qual, provavelmente, a professora conversa com os alunos a respeito de regras de boa convivência ${ }^{12}$.

E o que se pode observar? Primeiro, que a interpretação e a reprodução das letras são atividades trabalhosas para ele. E de que modo ele faz a cópia? Podemos fazer, a partir dos indícios de sua escrita, algumas conjecturas:

- Algumas palavras ele copia como quem copia traços que não têm sentido - como se fossem desenhos - e que, na falta de sentido, resta a ele o que percebe visualmente e o que consegue transcrever com traços próprios, como na regra 3 , em que é possível ver o amontoado de letras não interpretáveis Marapazazada o mateass adzgassa linpanizda, ou na regra 13, Vir gi ece umfazada, momentos em que RM possivelmente transcreve letra a letra o que supõe ser uma letra.

- Outras palavras - as quais provavelmente RM escreve repetidamente na escola - ele copia sabendo/interpretando o que copia, e registra, enquanto diz para si mesmo a palavra, na tentativa de selecionar a letra que supõe corresponder ao som que pronuncia. É o que ocorre no cabeçalho da tarefa: Línjua grafada com "J" no lugar de "G", já que, em outros contextos, as duas letras podem representar o mesmo som (como em viagem e viajar).

- Como na observação anterior, RM copia sabendo/interpretando o que copia, mas, ao escrever em seu caderno, registra as palavras como as pronuncia, $\mathrm{o}$ que corrobora nossa hipótese de que fala enquanto escreve. Por exemplo, as regras 10 e 13, em que escreve, respectivamente, Joga (para Jogar) e Fala (para Falar).

- No vai e vem dos olhos da lousa para o caderno e, talvez, para outros lugares, RM perde o fio da meada da cópia e repete pedaços da palavra, como no caso de Discicipluna; outras vezes, deixa de escrever parte(s) de uma palavra passando para a próxima linha, como no caso da regra 1 em que escreve só es para escola.

- RM parece ter mais dificuldade para interpretar o desenho de letras maiúsculas, talvez por serem usadas com menor frequência, se comparadas às minúsculas, como acontece na regra 12, em que escreve Oevantar para Levantar, ou na regra 16, em que visualiza um "Q" onde está escrito um "O" na palavra Obedecer, grafada por ele como Qbedecer.

- Algumas palavras formadas por letras cujo traçado manuscrito dificulta a percepção do seu início/final são mais difíceis de serem copiadas por RM. Observe-se como ele escreve, na regra 4, a palavra favor. Aanvor, na regra 12, braço, eraçodo ; e na regra 15, prova, piof vo. O registro manuscrito das letras "V" (em favor e prova) e "B" (em braço) exige um traço curvilíneo seguido de uma pequena reta que se junta à letra seguinte, configurando um contexto laborioso para a representação gráfica.

\footnotetext{
${ }^{12}$ Tivemos um problema na captura da imagem do caderno, razão pela qual a figura da coluna à esquerda apresenta as regras de $1 \mathrm{a} 4 \mathrm{e}$, em seguida, as de 10 a 20.
} 
- Quando a sílaba é representada por mais de duas letras, é comum que RM inverta a ordem delas, como em lixieira para lixeira (regra 10).

Esses erros na escrita de RM são uma amostra de vários aspectos imbricados no seu processo de aquisição e uso da escrita. $\mathrm{O}$ sujeito que se vê às voltas com o sistema de escrita do Português do Brasil (PB) precisa conhecer o alfabeto as letras - e as regras ortográficas. Historicamente, o sistema deixou de ser uma representação fonética da fala para se tornar "uma forma gráfica que permite a leitura" porque apaga/padroniza as variedades linguísticas características da fala (CAGLIARI, 1999/2008, p. 98-99). Assim, o aluno precisa saber fazer/desenhar as letras que compõem o nosso o alfabeto e quais combinações são possíveis entre elas (a letra "Q" é sempre seguida de "U”, não se usa "Ç” seguido de "I" ou "E", etc.); quais delas mantêm uma relação unívoca com um som da língua ("B" é /b/, "D" é /d/, "F" é /f/, etc), quais podem representar mais de um som ("S" pode ser /s/ e /z/, "X" pode ser /z/, / /, /s/ e /ks/, etc.), que alguns sons podem ser registrados ortograficamente por mais de uma letra (o som /s/ pode ser representado, por exemplo, por "S", "C" ou "SS", a depender do contexto em que estiver inserido e da norma ortográfica estabelecida); que existe uma variedade grande de formas gráficas das letras que são também desenhadas de maneiras diferentes pelas pessoas.

Tanto o reconhecimento quanto a produção desse tipo especial de desenho seguem uma direção (da esquerda para a direita) e uma orientação (de cima para baixo). Além disso, o desenho de cada letra impõe certas restrições ao traçado que a define como tal, por exemplo, fazer o risco em outra direção implica desenhar letras diferentes, como no caso da letra de imprensa para as letras minúsculas "b", "d", "q", "p"; de maneira semelhante, aumentar a forma arredondada em letra manuscrita minúscula pode diferenciar um "a" de um "c", o que interfere no sentido da palavra, como se viu no Dado 3.

Dessas primeiras observações a respeito da escrita de RM, o que mais chamou a nossa atenção foi o desenho das letras, isto é, sua materialidade que (ainda) se impõe como segredo para ele, tanto ao interpretar suas formas, quanto ao produzi-las. Não saber o traçado de uma letra e/ou não saber interpretar o traçado de uma letra afasta RM do sentido, pois não permite que estabeleça uma relação entre som e letra que se mantenha, distanciando-se da função social da escrita (VYGOTSKY, 1934/1984).

Não queremos com isso dizer que ele nunca consegue ler/interpretar o que escreve ou o que é escrito pelo outro. O Dado 3 mostra que ele faz isso em alguns contextos, mas não em outros. E quando estabelece essa relação, apresenta dúvidas comuns a outros novatos na leitura e escrita: (i) quando é preciso apagar a letra para escrever, isto é, quando o nome da letra carrega consigo o som de uma vogal que coincidentemente corresponde à vogal a ser escrita (como no caso de camiseta grafada como camizta $^{13}$ ); (ii) quando mais de uma letra concorre naquele contexto de escrita, como no caso de ch e $x$ em xocolate ${ }^{14}$. Em sílabas CCV, segundo Abaurre (2001), a criança precisa decidir primeiro sobre o número de segmentos a serem representados e

\footnotetext{
${ }^{13}$ Dado de 16/novembro/2010, conforme diário de registro do acompanhamento longitudinal

${ }^{14}$ Dado de 19/outubro/2010.
} 
depois sobre a posição de cada um na estrutura da sílaba (o que descaracteriza o que se convencionou chamar de "troca de letras"). É o que ocorre no caso da escrita de preto: RM segue escrevendo a estrutura silábica que já domina (CV), tem dificuldade de preencher a segunda posição do ataque ramificado e situa o " $R$ " na coda (per no lugar de pre); depois de se ouvir falando reiteradamente preto, além de ouvir seu interlocutor repetindo, ajusta as posições na estrutura CCV e escreve preto ${ }^{15}$.

Foi, portanto, pensando em ajudá-lo a perceber/compreender a diversidade de formas das letras, que iniciamos um trabalho com vários tipos de letras manuscritas e impressas - tanto para a leitura quanto para a escrita, incluindo aquelas produzidas por meio do computador, aproveitando seu potencial material e simbólico (FREITAS, 2010), com vistas a dar relevância à organização bipolar da linguagem escrita (JAKOBSON, 1955/1970; 1969; FREIRE, 2005).

\section{A ORGANIZAÇÃO BIPOLAR DA/NA ESCRITA}

Em estudo anterior, Freire (2005) analisa o uso da leitura e da escrita com base nos conceitos de Jakobson sobre a organização bipolar da linguagem em níveis hierárquicos (JAKOBSON, 1955/1970; 1969). O autor é referência para os estudos da ND, sobretudo devido aos seus escritos sobre as afasias, retomados e ampliados com base em uma visão abrangente e pública de linguagem condicionada por fatores ântropo-culturais (COUDRY, 2002a, 2002b).

Segundo o autor, a linguagem tem duplo caráter: a produção verbal implica a seleção de elementos linguísticos e a combinação deles em unidades de complexidade mais elevada (JAKOBSON, 1969, p. 37). Dito de outro modo, a produção e a interpretação de qualquer unidade linguística (uma palavra, uma frase, um texto) colocam em operação dois mecanismos: (i) a comparação entre elementos semelhantes que pertencem a um mesmo paradigma e que, portanto, podem ser substituídos e (ii) a relação de um dado elemento com os elementos que o precedem e o sucedem e que pertencem a um mesmo sintagma.

Um nível hierárquico é qualitativa e estruturalmente diferente de outro e há, entre eles, uma "superposição de contextos cada vez maiores" (JAKOBSON, 1955/1970, p. 52). Cada nível - fonético-fonológico, sintático, semântico - tem, ele mesmo, uma organização hierárquica própria: a ordem dos fonemas que compõem uma palavra, por exemplo, é já uma sintaxe.

Isso quer dizer que a linguagem - em seus vários aspectos, isto é, em seus diferentes níveis de estruturação - lida simultaneamente com dois tipos de relações, daí sua natureza bipolar (JAKOBSON, 1955/1970). Uma delas, interna, de similaridade (ou equivalência) e outra, externa ou de contiguidade. A relação interna, ou de seleção, diz respeito à escolha de elementos da língua que podem co-ocorrer em um dado contexto verbal nos diferentes níveis hierárquicos, e a relação externa, ou de contiguidade, diz respeito à relação entre os elementos selecionados, isto é, à combinação entre eles.

\footnotetext{
${ }^{15}$ Dado de 24/maio/2011.
} 
Freire (2005) expande a explicação de Jakobson (1955/1970; 1969) sobre a organização bipolar da linguagem para o sistema de escrita alfabética. Segundo a autora, também esse sistema se organiza em função de séries de seleções e combinações intercaladas em cada nível hierárquico que resultam, para cada um deles, em um repertório de complexidade crescente (letras possíveis, marcas morfológicas, itens lexicais, regras sintáticas próprias da escrita) e que funciona de maneira integrada no exercício da linguagem escrita (o conjunto de letras é condição de possibilidade dos arranjos morfossintáticos que, por sua vez, possibilitam a formação de palavras e assim sucessivamente).

Assim, o trabalho do sujeito com o sistema de escrita alfabético pode ser visto como uma sucessão de seleções e combinações estabilizada por fatores histórico-culturais. Esse deslocamento pelos dois eixos é da ordem do sistema da língua, vinculado a outros processos: a percepção visual e espacial, a gestualidade. Oscilações no deslocamento em si e/ou na sua relação com esses processos cognitivos, especialmente na fase inicial de aquisição, podem explicar algumas formas não convencionais de escrita e/ou hipóteses e dificuldades que surgem no seu acontecimento. Trata-se, como já foi dito, de um processo complexo, uma vez que as seleções e combinações que caracterizam a escrita e a leitura se referem, por sua vez, a seleções e combinações da fala e todas elas devem ser, em alguma medida, pareadas. Isso não significa que elas possam ser correlacionadas de forma biunívoca (uma letra pode representar mais de um som), tampouco que as seleções/combinações da fala precedem, necessariamente, as da leitura e da escrita. A leitura - realizada pela fala - é um lugar privilegiado, dado que, ao ler, o sujeito pode se certificar se o pareamento que fez ao escrever funciona, uma certeza que é dada pelo sentido (COUDRY, 2013).

Falar, ler, escrever, portanto, implicam o uso de um sistema que se organiza em função de um repertório próprio da língua - de sons e de letras que recursivamente origina um conjunto de recursos expressivos, que podem ser combinados de múltiplas maneiras em função de restrições de, pelo menos, dois tipos: (i) aquelas ditadas pelo próprio sistema, (ii) as que resultam da relação desse sistema com outros sistemas não verbais, ambas em conformidade com as condições de produção de um registro particular.

Queremos com isso dizer que, assim como aprender a falar pressupõe o ajuste sinérgico de uma série de estruturas do aparelho fonador do sujeito - abertura dos lábios, posicionamento da língua, coordenação pneumo-fônica, etc. -, também a escrita pressupõe o trabalho coordenado de vários processos - percepção visual e espacial, gestualidade - com os quais a língua mantém uma vinculação estreita, seja pela fala, seja pela escrita.

Foi levando em conta as observações que fizemos ao longo do acompanhamento longitudinal de RM, em especial sobre a sua relação com o desenho e com o traçado de letras, que introduzimos o computador para escrever, paralelamente à escrita usando lápis e papel. Nosso objetivo, ao explorar a materialidade do computador, que supõe outro gesto para escrever, é observar a relação de RM com a escrita em um contexto em que não é preciso lembrar a forma das letras, tampouco desenhá-las. 
SELECIONAR E COMBINAR TECLAS PARA ESCREVER

O gesto contínuo da escrita manuscrita em papel se torna discreto quando mediado pelo computador. Os desenhos das letras, feitos minuciosamente com o lápis, estão à disposição do escrevente no teclado do computador. As letras seguem um padrão conhecido por QWERTY, diferente da ordem alfabética aprendida pelas crianças na escola. À medida que se escreve no papel, os olhos seguem/ interpretam o contorno das letras e a mão pode interromper e/ou refazer quando se identifica um equívoco, um traço mal feito; no computador, os olhos se alternam do teclado para a tela e quando uma letra sai no lugar de outra, recorre-se a uma tecla especial que tem a função de apagar a letra indesejada. Quando não, a depender do editor de textos, a palavra aparece sublinhada em vermelho, oferecendo ao escrevente um retorno, uma primeira leitura, da sua escrita. Acentuar e pontuar no computador, muitas vezes, requer o uso combinado de duas teclas; a segmentação de palavras exige a breve interrupção do gesto de escrever quando se usa lápis e papel; no computador, o espaço em branco é marcado pelo gesto de apertar uma tecla especial. O que se vê no teclado poucas vezes corresponde ao que se vê na tela: o que se pretende escrever, por exemplo, CASA ganha forma nova: casa, casa, casa, casa, sendo ainda a mesma palavra.

Assim, considerando as peculiaridades de escrever usando o computador, sobretudo o fato de o sujeito dispor do conjunto de letras que formam o alfabeto e prescindir da tarefa de desenhá-las, durante vários encontros com RM nos dedicamos à produção de um texto sobre suas brincadeiras - histórias de faz-de-conta habitadas por super-heróis, robôs e monstros - motivado que fora pela leitura conjunta que fizemos do livro O Menino Maluquinho ${ }^{16}$. Durante a sua elaboração, RM escreveu à mão e usando o computador, fez buscas de figuras na internet, desenhou, criando um texto multimodal (KLEIMAN, 2005) em que o desenho não é mais condição necessária para a interpretação do outro, mas sim uma forma de ilustrar o que se escreve ampliando a interpretação, tal como é no livro do Menino Maluquinho. Terminada a história, transformamos parte dela em um vídeo, no qual RM ensina como construir uma máscara de robô usando uma caixa de papelão.

Nosso interesse em investir em práticas de linguagem como essas é múltiplo. De maneira geral, por se tratar de uma atividade duradoura, o sujeito precisa planejar, retomar e revisar o que será e/ou o que já foi feito e as cuidadoras podem, então, observar e intervir nos processos de atenção mobilizados pela criança para se manter na atividade, uma queixa escolar recorrente no caso de RM. Outro aspecto importante diz respeito ao movimento entre a fala, a leitura e a escrita. No vídeo, RM protagoniza um apresentador de TV, semelhante ao programa Art Attack da Disney Channel, ao qual assiste com frequência. Como tal, assume um registro formal de fala e se movimenta com desenvoltura diante da câmera. Faz passo a passo a máscara, enquanto informa ao espectador sobre os materiais ou os procedimentos que deve realizar.

${ }^{16}$ Livro de Ziraldo (Ziraldo Alves Pinto) lançado em 1980 e que foi criteriosamente escolhido por nós com o propósito de provocar uma identificação positiva entre RM e o Maluquinho. 
Terminada a fase de gravação do vídeo ${ }^{17}$, assistimos juntos e resolvemos editálo, de modo que inseríssemos entre as fases da confecção da máscara - recortar uma caixa de papelão, fazer os olhos e nariz, colocar os dentes e cabelo, pintar - algumas telas informando, por escrito, tal como é comum aparecer em programas de TV deste tipo, a lista de materiais e os procedimentos a serem seguidos ${ }^{18}$.

Começamos, então, a escrever as informações a partir do material que era ouvido por meio da gravação. Era necessário ouvir com atenção e traduzir o que era dito de maneira espontânea na fala - embora com um registro formal- para a escrita, seguindo um texto de natureza instrucional. Nesse trabalho, o pareamento entre fala e escrita era intenso e RM pôde perceber as diferenças entre as duas formas de dizer, não só em relação à grafia padronizada pela escrita - que apaga a variedade de sua fala - como também em relação à organização do texto, em conformidade com o texto instrucional, que faz uso de certas estruturas e não de outras (como a do tempo verbal no imperativo).

Para escrever, usamos lápis e papel, bem como diferentes tipos de editores de texto em vários computadores. Nosso propósito não era substituir a letra manuscrita pela digitação; ao contrário, além de considerarmos ambas relevantes para o sujeito - sendo a primeira uma importante marca de subjetividade (FREIRE, 2005) -, nosso foco estava na possibilidade de RM vivenciar visual e gestualmente as diferenças entre elas para que percebesse a unidade da letra (MASSINI-CAGLIARI, 1999/2008). A diversidade de computadores que têm vários tipos de entradas de dados - pelo teclado, mouse, tela de toque - demanda outros gestos para escrever e tornam a escrita discreta, oferecendo ao sujeito um contato imediato com as diferenças entre as letras.

Nesse percurso, pudemos observar e intervir em vários aspectos relacionados de maneira especial à escrita. Veja-se o Dado-achado 4 a seguir. No encontro, RM usou o teclado de um tablet para escrever a primeira das instruções a serem inseridas no vídeo: (1) recorte a caixa de papelão embaixo. O enunciado foi construído oralmente e de forma dialógica - entre RM e as cuidadoras - após a exibição da parte inicial do vídeo, ocasião em que tentávamos mostrar a ele que uma instrução deveria ser a descrição passo-a-passo da confecção da máscara do robô, tal como ocorre em uma receita culinária ou em instruções para a construção de brinquedos. Devido à extensão do dado, apresentamos aqui alguns excertos que totalizam 3 minutos de gravação, indicando a hora do acontecimento do que se mostrou, em nossa análise, um achado ou um indício (ABAURRE e COUDRY, 2008).

${ }^{17}$ Embora o desenvolvimento dessa prática de linguagem possa parecer ao leitor sequencial, esclarecemos que ela se estendeu por quase um ano e que foi entremeada por muitas outras envolvendo a fala, a leitura, a escrita, o cálculo, noções de tempo-espaço e conteúdos escolares em consonância com os acontecimentos da vida: o que RM tinha para contar, as conversar que aconteciam no grupo do CCazinho, as notícias dos telejornais, o cotidiano da escola, etc.

${ }^{18}$ A edição e finalização do vídeo foram feitas por Iak. 
07':08” - RM: Que que é esse “i” esquisito?

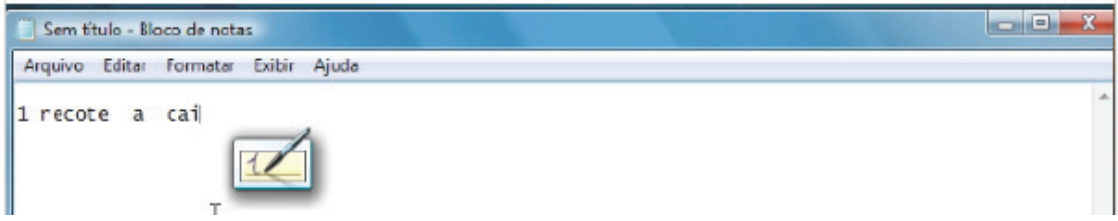

Sem querer, RM toca a tela com o indicador, ativando a tela de toque

$08^{\prime}: 37$ ' - RM: Como se escreve lã?

\begin{tabular}{|l|l|l|}
\hline Sem título-Bloco de notas & arquivo Editar Formatar Exibir Ajula & . \\
\hline 1 recote a caixa depape1 & \\
\hline
\end{tabular}

Digita o "l" e fica olhando para a tela

08 ':42" - RM: O que que é isso?

09':14" - RM: O "ele" tá ao contrário.

09':16" - Iff: Não. É esse tipo de letra. Cada letra tem vários tipos de formato. E nesse, o desenho dela é assim.

\begin{tabular}{|c|c|}
\hline Dem ttulo - Eloco de notas & 0 미 $x$ \\
\hline Arquivo Editer Formstar Exibir Ajuds & \\
\hline
\end{tabular}

09':16" - Sem querer RM aperta a tecla "ç" que fica ao lado da tecla do "l"

\begin{tabular}{||l||}
\hline Arquivo Edtar Formatar Exbir Ajuda \\
\hline 1 recote a caixa de papelçlll|
\end{tabular}

Em seguida digita duas vezes o "l"

\begin{tabular}{|l|l|l|}
\hline Sen tîulo-Bloco de notas & Arquivo Edtar Formatar Exibir Ajuda \\
\hline 1 recote a caixa de papel11111
\end{tabular}

09':30" - A sequência “çll” é apagada por Iff para que RM continue a escrever $R M$ digita várias vezes a letra "l"

09”:41” - RM: Parece o “i”...

\begin{tabular}{|c|c|}
\hline Dem título - Bloco de notas & 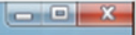 \\
\hline Arquivo Edizar Formatar Exikir Ajuda & \\
\hline
\end{tabular}

10':09" - Sem querer, RM clica fora da área do Bloco de Notas.

Ao retornar, clica entre as letras " $a$ " $e$ " $i$ " da palavra "caixa" e digita a letra " $l$ "

Dado 4 - [13/08/2011] RM escreve a instrução: recorte a caixa de papelão embaixo (9a11m; $4^{\circ}$ ano EF). 
Denominamos de dado-achado (COUDRY, 1996) esse episódio exatamente pela sua peculiaridade, que nos faz olhar para o trabalho do sujeito de um outro lugar, retirando-nos da cena enunciativa em questão e dirigindo a nossa atenção para o caráter deliberado com que o sujeito seleciona certas letras que não correspondem à nossa expectativa, isto é, não combinam com aquilo que RM pretende escrever, informando-nos sobre onde está o sujeito no processo.

Nesse encontro, utilizamos o bloco de notas do tablet, um editor de textos simples, cuja fonte padrão é Lucida Console. Nesta fonte, a letra $i$ minúscula é grafada como $i$, causando estranheza a RM que, provavelmente, tem em mente uma outra representação geométrica para a letra, o que o leva a dizer para as cuidadoras: “Que que é esse 'i’ esquisito?”. A atividade prossegue, mas RM se vê diante da mesma questão ao escrever a sílaba "lã". Ao digitar a letra "L", cuja aparência na tela é “†”, observa a tela e diz: "O “ele’ tá ao contrário". A explicação de Iff não é suficiente para esclarecer sua dúvida. A letra “7” está mesmo de pontacabeça, se levarmos em conta a aparência da letra no teclado, "L".

Em seguida, pelo fato de manter fixo seu olhar na tela sem desviá-lo para o teclado, aperta a tecla do "Ç" ao invés da tecla do "L" e, depois, deliberadamente, digita duas vezes "L", alternando seu olhar do teclado para a tela, provavelmente para comparar as duas representações gráficas da letra, a do teclado e a da tela. Iff interfere na atividade na tentativa de fazer com que RM desse continuidade à escrita de papelão, apagando a sequência "ÇLL". Mesmo assim, deliberadamente, RM digita mais uma vez, outra sequência de "L", certificando-se de que o que via no teclado e na tela não era o que pensara: "Parece o 'i'", diz ele.

Na sequência, aproveitando-se de um pequeno deslize - teclar fora da área do bloco de notas, o que ativa a tela de toque e o obriga a clicar novamente no editor -, leva o cursor entre as letras "A" e "i" da palavra caixa e insere um "L" ca 1 ixa - aproximando espacialmente as duas letras enigmáticas para comprovar que eram diferentes entre si, embora ambas não correspondessem à representação esperada/imaginada para elas.

Terminado o registro dessa primeira instrução, voltamos para que ele a lesse em voz alta. Passar pela fala, como já foi dito, ajuda o sujeito a parear letras e sons e a reconhecer (ou não) no que escreveu palavras da língua. Quando não é possível proceder à leitura de forma autônoma, intervimos e lemos em conjunto. É nesse momento que RM percebe a falta de um som na palavra recote, que representaria a posição da coda nessa estrutura. O primeiro passo é selecionar qual letra corresponde àquele som. As cuidadoras pronunciam a palavra de várias maneiras imitando diferentes variedades regionais: a carioca, a paulistana, a paulista. Sem dificuldade, RM seleciona a letra "R" e passa, então, a lidar com a combinação possível para escrever a palavra recorte, como se pode ver no Dado-achado 5.

$1^{\mathrm{a}}$ tentativa: recotre

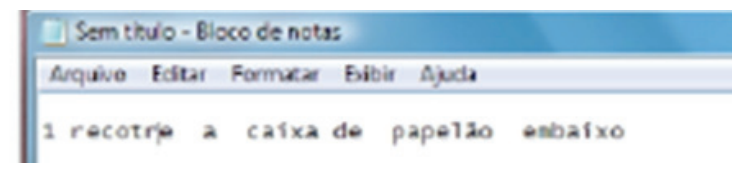


$2^{\mathrm{a}}$ tentativa: recoter

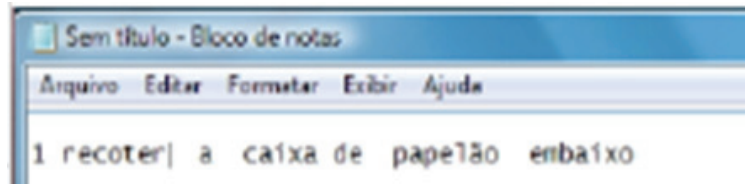

$3^{a}$ tentativa: recrote

\begin{tabular}{l} 
Sem titulo-Bloco de notas \\
\hline Arquive Fditar Fermatat Esibir Ajuda \\
\hline recrote a caixa de papelalo enbaixo
\end{tabular}

$4^{\mathrm{a}}$ tentativa: recorte

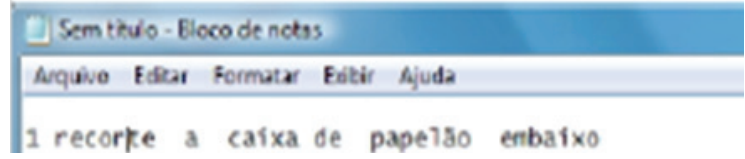

Dado 5 - [13/08/2011] RM reescreve a palavra recote $\left(9 \mathrm{a} 11 \mathrm{~m} ; 4^{\circ}\right.$ ano $\left.\mathrm{EF}\right)$.

Para combinar, RM parece se servir de algumas estratégias. Começa pela última sílaba, sabedor que é de que na primeira não pode ser, pois a palavra começa com "R". Não consegue reconhecer se a estrutura interna da sílaba é consoante/consoante/vogal (CCV) ou consoante/vogal/consoante (CVC). Nos dados selecionados, tal como mostra Abaurre (2001), RM constrói primeiro a estrutura silábica marcada $(\mathrm{CV})$ e estão em construção sílabas com estrutura mais complexa, CCV e CVC. RM insere o R em lugares possíveis, como coda (teR) e ataque ramificado (tRe; cRo), até acertar a posição de coda na segunda sílaba, a única complexa (CVC). Chamamos a atenção ainda para a possibilidade oferecida pelo computador de passear pelas letras da palavra, o que facilita a visualização da combinação entre as letras, permitindo ao sujeito ler em voz alta cada combinação que faz, reforçando o trajeto da fala para a escrita e da escrita para a fala, desejável e necessário para a aquisição da leitura e escrita (BORDIN, 2010).

\section{CONSIDERAÇÕES FINAIS}

Apresentamos o sujeito RM, em um momento específico de sua história com a escrita, considerando a queixa da escola de que ele não consegue ler e escrever, não consegue se manter nas atividades escolares. Apresentamos também uma criança esperta, que quando se vê às voltas com práticas de linguagem que lhe dizem respeito e que convocam a sua participação no lugar de quem tem o que dizer/escrever, como ensinar a confeccionar uma máscara de robô de papelão, mantém-se na atividade ainda que sejam necessários 3 minutos para saber se o que pensa que vê é o que vê (Dado 4). 
Analisamos dois recortes do primeiro ano do acompanhamento longitudinal de RM tentando responder a uma interrogação: o que será que ele está tentando lembrar quando diz para si mesmo [Ga] [Ga] [Ga] ao escrever garagem no Dado 2? Está tentando parear o que diz com a escrita, atento ao som que produz e tentando selecionar a letra que na escrita o representa? Está tentando lembrar a forma da letra "G" que ele sabe que representa o som que produz? Está tentando lembrar o nome da letra, cuja forma ele tem na cabeça e sabe que representa o som que produz, para poder dizer a Iff, aguardando sua confirmação? Está tentando fazer as três coisas? A única certeza é a de que a escrita de uma única letra que inicia uma única palavra da língua é um processo complexo que supõe a concomitância de vários processos/saberes, e era nesse imbricado processo que tínhamos que interferir. Nesse sentido, o uso do computador fez diferença.

Seus traços feitos a lápis mudavam de tal forma que era difícil estabelecer relações entre sons e letras, afastando-o do sentido do registro. Sem conseguir manter traços próprios, não lhe era possível estabelecer correlações entre os seus e os do outro (em especial, professora e cuidadoras). Eram linhas e curvas que, muitas vezes, não representavam palavras da língua. $\mathrm{O}$ computador o isentou das tarefas de ter que se lembrar do repertório de letras e, também, de ter que saber traçar cada letra, ora usando letra bastão, ora manuscrita, e foi por isso que, pouco a pouco, RM percebeu, em um amontoado de traços, sentidos já conhecidos e novos.

A seleção das letras do teclado, a manipulação do cursor para encontrar o lugar exato da letra, a visualização das formas das letras que muitas vezes não correspondem às formas que vê no teclado, o uso ordenado de teclas para compor uma letra acentuada, o uso de uma tecla grande para definir espacialmente uma palavra, todas essas ações aqui interpretadas como seleções e combinações, consistem em um jogo com a escrita por meio do qual RM pôde comparar partes dos traços das letras, atento a semelhanças e diferenças entre elas e, assim, entrar na escrita articulando suas faces visual, cinestésica (motora) e a do sentido. Um jogo que requer organização e atenção, características que faltavam a RM. Somese a esse exercício reflexivo o fato de RM, paralelamente, ler e escrever com a sua própria caligrafia e ser convocado a ler a escrita de outras pessoas.

Foi por meio desse jogo e do vai-e-vem entre formas de letras que RM respondeu à nossa interrogação inicial. Usando o computador, RM analisou meticulosamente as letras - "que que é esse $i$ esquisito"; "o 'ele' tá ao contrário..."; "parece o ' $i$ '- em uma mistura de atividades epi e metalinguísticas, e pôde relacioná-las a sons checando seus valores em relação a outras letras que as antecedem ou sucedem. O traço não só lhe era penoso, como também opaco. Entre lápis e teclas, a questão de RM para entrar no mundo das letras parece ser a mesma: selecionar traços, pontos e curvas à mão; selecionar formas diversas de letras, cujos traços, pontos e curvas já estão postos. Nas duas situações, RM funciona de maneira quase unipolar, isto é, mantém-se na seleção e, por isso mesmo, tem poucas condições para combinar. A escrita no computador lhe deu a chance de estabelecer diferenças entre as letras de um modo menos ambíguo, o que permite que se aproxime do sentido. 
E o que se pode falar a respeito do caso clínico de RM? Do ponto de vista neurolinguístico, não é possível dizer que ele apresenta um problema orgânico que justifique suas dificuldades escolares. É fato que elas existem e persistem. É verdade que na primeira infância RM teve um quadro de epilepsia, mas o exame neurológico realizado em novembro de 2011 não mostra alteração. $\mathrm{O}$ medicamento foi descontinuado desde então e RM não apresentou nenhum episódio neurológico. O que se pode dizer é que a sua vida familiar é conflituosa, o que incide negativamente na escola. O acompanhamento longitudinal no CCazinho, como os dados mostram, modificou sua relação com a leitura e a escrita. Hoje, RM lê e escreve, embora não se atenha sempre à escrita ortográfica; falta-lhe, ainda, fluência e autonomia. Sua caligrafia melhorou muito, a ponto de poder ler o que escreve. É capaz também de ler o que outra pessoa escreve e copiar, mas a cópia ainda é lenta. E a escola? Neste ano de 2013, RM mudou de escola. Está no $6^{\circ}$ ano e tem um professor para cada disciplina, o que funciona como um fator complicador para ele. A maior parte dos professores mantém uma rotina de trabalho semelhante: copiam textos na lousa para que os alunos os copiem. RM não consegue manter o ritmo das aulas e das atividades. A escola que frequenta é estadual, oferece os livros didáticos, mas os alunos não podem levá-los para casa. E como RM estuda em casa? Seus cadernos têm muitas páginas em branco e, sem os livros, não the é possível criar uma memória sobre o que vê/ouve em sala de aula todos os dias. Barrado na leitura e na escrita por muito tempo, os conteúdos escolares ficam para trás. RM não acompanha boa parte do discurso que circula na escola. A Matemática tem sido um desafio para ele. Observamos que as questões vísuo-espaciais focalizadas neste artigo reaparecem na montagem das quatro operações, especialmente na divisão, a mais complexa delas.

O primeiro ano do acompanhamento representa para nós a descoberta do que para RM estava cifrado impedindo sua entrada no sistema alfabético. A partir do fio de uma meada, a questão vísuo-espacial envolvida na escrita das letras, manuscritas e impressas, é que todas as atividades propostas foram organizadas e mostraram um caminho possível para RM trilhar. Esse é o papel do CCazinho.

\section{REFERÊNCIAS BIBLIOGRÁFICAS}

ABAURRE, M. B. M. (2001). Dados da escrita inicial: indícios de construção da hierarquia de constituintes silábicos? In: HERNANDORENA, C. L. M. (org.), Aquisição de língua materna e de língua estrangeira: aspectos fonético-fonológicos. Pelotas: EDUCAT/ALAB. Pp. 63-85. ; COUDRY, M. I. H. (2008) Em torno de sujeitos e de olhares. In: Estudos da Língua(gem). Vitória da Conquista, v. 6, n. 2 (p. 171-191).

BAKHTIN, M. (1952-53/1997) Os gêneros do discurso. In: BAKHTIN, M. Estética da Criação Verbal. São Paulo: Martins Fontes (p. 277-326). . (1929/1999) Marxismo e Filosofia da Linguagem. São Paulo: Hucitec.

BORDIN, S. S. (2010). Fala, Leitura e Escrita: encontro entre sujeitos. Tese de Doutorado em Linguística, Instituto de Estudos da Linguagem, Unicamp. 
CAGLIARI, L. C. (1999/2008) Sob o signo da ortografia. In: MASSINI-CAGLIARI, G.; CAGLIARI, L. C. (orgs.) Diante das letras: a escrita na alfabetização. Campinas, SP: Mercado de Letras. (p. 97-110).

COUDRY, M. I. H. (2013) Eu li a praca. Pírula ou Pílula. Encontro entre a sócio e a neurolinguística. In: BORBA, L.; LEITE, C. M. B. (orgs.). Diálogos entre língua, cultura e sociedade. Campinas: Editora Mercado de Letras.

. (2009). Despatologizar é preciso: a experiência do CCazinho. In: MARÇALO, M. J.; LIMA-HERNANDES, M. C.; ESTEVES, E.; FONSECA, M. do C.; GONÇALVES, O. (orgs.). A língua portuguesa: ultrapassar fronteiras, juntar culturas. Évora, Portugal: Universidade de Évora, v. 11. (p. 97-117).

. (2006) Patologia estabelecida e vivências com o escrito: o que será que dá? 2. In: $7^{\circ}$ Encontro Nacional sobre Aquisição da Linguagem (ENAL). Porto Alegre. (cd-rom).

- (2002a) Memorial apresentado à Banca Examinadora do Concurso de Livre-docência do Departamento de Linguística do Instituto de Estudos da Linguagem da Universidade Estadual de Campinas.

- (2002b) Conceitos de Afasia: clássico é clássico e vice-versa. Aula apresentada à Banca Examinadora do Concurso de Livre-docência do Departamento de Linguística do Instituto de Estudos da Linguagem da Universidade Estadual de Campinas.

(1996) O que é dado em neurolingüística? In: CASTRO, M. F. P. (org.) O Método e o dado no estudo da linguagem. Campinas: Editora da Unicamp. (p. 179-192).

. (1993) Neuropsicologia: aspectos biológicos e sociais. In: RODRIGUES, N.; MANSUR, L. L. (eds.) Temas em Neuropsicologia (Série de neuropsicologia; v. 1). São Paulo: Tec Art. (p. 38-57).

. (1986/1989) Diário de Narciso - discurso e afasia. São Paulo: Martins Fontes.

COUDRY, M. I. H.; FREIRE, F. M. P. (2005) O trabalho do cérebro e da linguagem: a vida e a sala de aula. Campinas, SP: Unicamp/Cefiel e MEC.

. (2010) Pressupostos teórico-clínicos da Neurolinguística Discursiva (ND). In: COUDRY, M. I. H.; FREIRE, F. M. P.; ANDRADE, M. L.; SILVA, M. A. (orgs.). Caminhos da Neurolinguística Discursiva: teorização e práticas com a linguagem. Campinas: Mercado de Letras. (p. 23-48).

FRANCHI, C. (1977/1992) Linguagem - Atividade Constitutiva. In: Cadernos de Estudos Lingüísticos. Campinas: (22): 9-39.

FREITAS, M. T. de A. (2010). A perspectiva vigotskyana e as tecnologias. In: História da Pedagogia. São Paulo, SP: Editora Segmento. (p. 58-67).

FREIRE, F. M. P. (2012). Escola e tecnologia: um olhar discursivo sobre essa complexa relação. In: Livro de Atas do II Congresso Internacional TIC e Educação. Lisboa/Portugal: Instituto de Educação da Universidade de Lisboa,. v.1. p.513 - 533.

. (2011) Práticas digitais informais e leitura/escrita formais. In: Anais do XVI Congreso Internacional de la Asociación de Lingüística y Filología de la América Latina (ALFAL). Alcalá de Henares. (p. 1-10).

. (2005). Agenda Mágica: linguagem e memória. Tese de Doutorado em Linguística, Instituto de Estudos da Linguagem, Unicamp.

FREUD, S. (1891/1973) La afasia. Tradução de Ramón Alcalde. Buenos Aires, Ediciones Nueva Visión.

GERAldI, J. W. (1991/1993) Portos de Passagem. São Paulo: Editora Martins Fontes.

JAKOBSON, R. (1969) Dois aspectos de linguagem e dois tipos de afasia. In: JAKOBSON, R. (org.) Lingüística e Comunicação. São Paulo: Cultrix. (p. 34-62).

. (1955/1970) A afasia como problema lingüístico. In: COELHO, M.; LEMLE, M.; LEITE, Y. (orgs.) Novas Perspectivas Lingüisticas. Petrópolis: Vozes. (p. 43-54). 
Cadernos de ESTUDOS LINGḯlsTICOS (55.2) - Jul./Dez. 2013

KLEIMAN, A. B. (2005). Preciso "ensinar" o letramento? Não basta ensinar a ler e escrever? Campinas, SP: Unicamp/Cefiel e MEC.

LURIA, A. R. (1981) Fundamentos de Neuropsicologia. São Paulo: Cultrix.

MASSINI-CAGLIARI, G (1999/2008) Aquisição da escrita: questões de categorização gráfica. In: MASSINI-CAGLIARI, G.; CAGLIARI, L. C. (orgs.) Diante das letras: a escrita na alfabetização. Campinas, SP: Mercado de Letras. (p. 49-59).

VYGOTSKY, L. S. (1934/1984) A Formação Social da Mente. São Paulo, SP: Martins Fontes. 